\title{
Bases da legitimidade democrática no Brasil: adesão a valores e avaliação de desempenho'
}

\author{
Ednaldo Aparecido Ribeiro \\ Universidade Estadual de Maringá
}

\begin{abstract}
Resumo
Estudos recentes sobre legitimidade democrática têm seguido uma perspectiva idealista que enfatiza a adesão dos cidadãos a valores fundamentais desta forma de governo. Alguns autores, entretanto, têm indicado que essa abordagem pode não ser adequada para a análise sobre países sem longa tradição democrática, propondo como alternativa um modelo realista que enfatiza como variável independente a avaliação de desempenho institucional. O presente artigo pretende contribuir para esse debate testando esse modelo alternativo para o caso brasileiro, utilizando dados produzidos pelo projeto World Values Surveys. Os resultados indicam que variáveis relacionadas a avaliações objetivas acerca do desempenho das instituições e das lideranças políticas têm um impacto maior sobre os níveis de legitimidade, em comparação com as variáveis referentes à adesão a valores.
\end{abstract}

Palavras-chaves: legitimidade política, democracia, desempenho, valores políticos.

\begin{abstract}
Recent studies about democratic legitimacy have been proceeding an idealistic perspective that emphasizes the adhesion of the citizens to value fundamental this government way. Some authors, however, have been indicating that approach cannot be adapted for the analysis of countries without long democratic tradition, proposing as alternative a realistic model that emphasizes as independent variable the evaluation of institutional performance. The article intends to contribute for that debate testing that alternative model for the Brazilian case, using data produced by the project World Values Surveys. The results indicate that varied related to objective evaluations concerning the performance of the institutions and of the political leaderships have a larger impact on the legitimacy levels, in comparison with the referring variables to the adhesion to value.
\end{abstract}

Key words: political legitimacy, democracy, performance, political values.

\footnotetext{
${ }^{1}$ Agradeço aos pareceristas anônimos de Opinião Pública pelas sugestões feitas.
} 
RIBEIRO, E. A.Bases da legitimidade democrática no Brasil: adesão a valores e avaliação...

A partir da segunda metade do século XX tornou se recorrente nas análises políticas a adoção de modelos explicativos próprios da economia, que apesar da sua significativa diversidade interna, pretendem elucidar o comportamento social e político a partir de princípios oriundos da ciência econômica. De uma forma geral, os adeptos dessa perspectiva compartilham o pressuposto básico de que a análise deve se debruçar sobre o nível individual, entendendo os atores políticos ou sociais como dotados de recursos e capacidades para tomar decisões que produzam a maximização de benefícios tendo em vista seus objetivos específicos (DOWNS, 1999; BECKER, 1976; OLSON, 1999; COLEMAN, 1990).

Desde as suas primeiras formulações, tal abordagem tem gerado intensos debates nos quais tendem a se opor o homo economicus ao homo sociologicus. A polêmica se justifica, pois tal explicação se opõe as teorias sociológicas clássicas e contemporâneas que tratam de afirmar que os fenômenos sociais são mais adequadamente compreendidos a partir da análise de processos de socialização que constroem uma unidade de valores, padrões de comportamentos ou papéis sociais que orientam os atores em suas práticas.

Sem a pretensão de nos posicionarmos radicalmente em um campo ou outro desta disputa, neste trabalho pretendemos apresentar uma proposta de análise acerca do rendimento desta perspectiva racionalista para o campo específico dos estudos sobre legitimidade democrática e, mais especificamente ainda, no contexto da jovem democracia brasileira.

O tema da legitimidade é particularmente interessante para essa discussão, pois desde as primeiras formulações teóricas a seu respeito (EASTON, 1965), podemos verificar um esforço no sentido de estabelecer um caminho intermediário entre a racionalidade e a socialização dos indivíduos para a explicação dos níveis de apoio dispensados a determinados objetos que compõem os sistemas políticos.

Tentando contribuir minimamente para essa discussão, na primeira parte deste artigo, apresentamos uma revisão acerca das possíveis relações entre essa abordagem racionalista e os estudos sobre legitimidade em regimes democráticos. Nossa atenção neste momento se volta especialmente para a interessante combinação de fatores que configura a proposta multidimensional de Easton.

Na seqüência, utilizando dados produzidos pelo projeto World Values Surveys, analisamos a validade e potencialidade de uma abordagem racionalista ou realista na explicação dos níveis de legitimidade da jovem democracia brasileira.

Uma vez que a teoria clássica da legitimidade, bem como parte importante das sofisticações posteriores, foi produzida para ser aplicada às nações dotadas de uma longa tradição democrática, nossa intenção é verificar se a combinação do homo economicus com o homo sociologicus se mostra pertinente também para a análise do tema em realidades distintas, como a nossa. 
Avaliação racional, valores políticos e a questão da legitimidade

O estudo das decisões como se fossem tomadas racionalmente (DOWNS, 1999), um princípio básico da explicação econômica, foi incorporado pelas demais ciências sociais no curso das últimas décadas. Na realidade, esse pressuposto racionalista pode ser interpretado como simplificação metodológica justificável diante da intenção de prever ou explicar os comportamentos humanos, uma vez que uma ação aleatória e desprovida de racionalidade é em essência indecifrável.

A suposição do ordenamento e padronização do comportamento humano é, portanto, o ponto de partida dos economistas e a base para o que se denominou de teoria da escolha racional, amplamente aplicada aos estudos dos fenômenos sociais e políticos.

A lista dos autores que contribuíram para a formulação dessa perspectiva, na sua maioria economistas, é imensa e qualquer tentativa de revisão exaustiva fracassaria pelas lacunas deixadas ou pela superficialidade no tratamento. Merecem destaque, entretanto, algumas obras referenciais: Anthony Downs, em 1957, adota os pressupostos da racionalidade para explicar o comportamento político do governo, partidos e eleitores na democracia moderna, construindo uma teoria econômica dessa forma de governo (1999); Gary Becker propôs um modelo que pretendia explicar o comportamento familiar (ou estratégias familiares) a partir da premissa fundamental de que os indivíduos tendem a desenvolver estratégias de maximização de seus recursos (1976); Mancur Olson, por sua vez, adota argumentos semelhantes para explicar a ação coletiva em grupos políticos (1999); James Coleman apresenta uma sistemática teoria que emprega um modelo microeconômico para explicar os mais variados aspectos da organização social em seu Fundations of social theory (1990).

Neste artigo, pretendemos verificar se os argumentos básicos dessa perspectiva podem ser igualmente interessantes para a análise do tema da legitimidade, em especial em contextos nos quais os valores democráticos ainda não têm uma existência consolidada.

A idéia de que os atores políticos são capazes de produzir avaliações racionais acerca do desempenho de instituições e lideranças políticas específicas esteve presente deste a formulação inicial proposta por Easton para o estudo do tema. A perspectiva projetada no nível teórico por esse autor apontava para a existência de dois níveis de apoio ao regime: o difuso e o específico (EASTON, 1968). No primeiro nível estariam os valores básicos ligados à aceitação abstrata dos princípios fundamentais do regime democrático. O segundo seria composto por fenômenos específicos, principalmente ligados às avaliações acerca do funcionamento concreto das instituições que compõem o regime político e o desempenho dos seus operadores, ou seja, as elites. 
O primeiro nível da legitimidade, portanto, aponta para a importância de processos prolongados de socialização política dos indivíduos que, submetidos a experiências no interior de instituições como a família e a escola, internalizariam valores de apoio ou rejeição ao sistema e as suas partes constituintes.

Esse processo de formação de valores e atitudes favoráveis à democracia envolve um complexo de fatores, pois não se dá apenas nos primeiros anos da vida dos indivíduos, em um suposto período de recepção que podemos chamar de socialização infantil. Experiências na fase pré-adulta e também na maturidade teriam importância fundamental para a configuração das orientações políticas (ALMOND \& VERBA, 1989). Na medida em que as pessoas vivenciam suas experiências sociais em espaços distintos como a família, a escola, clubes sociais, sindicatos, associações de moradores, dentre outros, os seus valores, atitudes e comportamentos vão sendo formados e/ou alterados (ALMOND \& POWELL, 1972).

É a continuidade na incorporação e alteração de valores e crenças básicas que nos remete à segunda dimensão da legitimidade, pois o apoio pode ser afetado no curto prazo por desempenhos conjunturais positivos ou negativos por parte das instituições e das lideranças políticas. Neste caso, devemos considerar os cidadãos como capazes de avaliarem tais desempenhos e, conscientemente, apoiarem ou rejeitarem esses objetos políticos isoladamente ou o sistema político como um todo em razão dos benefícios que recebem.

Os efeitos das avaliações de desempenho negativas e a conseqüente redução do apoio específico, no entanto, não conduzem imediatamente ao declínio dos níveis de apoio difuso, pois essa adesão abstrata não depende de um cálculo racional totalmente consciente, mas de um relativamente longo processo de mudança de orientações subjetivas, como argumentamos acima.

Sendo assim, o fato de recentes estudos indicarem o declínio dos níveis de legitimidade democrática em escala mundial (NORRIS, 1999; PHARR, PUTNAM e DALTON, 2000; DALTON, 2004) pode não significar imediatamente um risco para as democracias, pois o apoio difuso funcionaria como uma reserva que poderia minimizar os efeitos da redução no nível específico. Alguns autores chegam a considerar que na democracia certo grau de desconfiança em relação às instituições seja indicação de um saudável distanciamento do cidadão em relação aos assuntos públicos que não domina plenamente (WARREN, 2001; PETTIT, 1998). É claro que, como toda reserva, trata-se de algo finito que pode não resistir a sucessivos períodos de desempenho político insatisfatório. Tal situação é potencialmente perigosa para democracias que ainda lutam para solidificar sua legitimidade entre os cidadãos (EASTON, 1968; NEWTON e NORRIS, 2000).

Essa compreensão sobre a legitimidade foi aceita e sofisticada por trabalhos teóricos mais recentes que trataram de identificar categorias mais específicas de objetos alvos do apoio ou da rejeição dos indivíduos. Norris (1999), por exemplo, 
identifica como objetos a comunidade política, os princípios do regime, o desempenho das suas instituições e os líderes políticos. Essas dimensões específicas recentemente foram empiricamente confirmadas por Seligson, Booth e Gómez (2006) em pesquisa realizada com a população da Costa Rica. Apesar da subdivisão, salientamos que as dimensões difusa e específica permanecem presentes.

Mishler e Rose (2001), entretanto, denunciam que parte significativa dos estudos empíricos sobre legitimidade não tem acompanhado essa tendência multidimensional. Alertam para o fato de que diversos pesquisadores têm produzido medidas de apoio político orientados por uma abordagem idealista, que privilegia variáveis relacionadas à adesão dos cidadãos aos princípios ou idéias do regime democrático, ou seja, o que na terminologia de Easton é denominado de apoio difuso. Ainda que tal medida seja útil em países com democracias estáveis, os autores apontam que tal procedimento pode não ser adequado para avaliar a legitimidade em jovens democracias com passado autoritário e futuro relativamente incerto (MISHLER e ROSE, p. 303).

Para esses contextos, propõem uma abordagem realista que enfatiza a avaliação dos cidadãos das jovens democracias acerca do desempenho dos novos regimes em comparação com períodos anteriores, portanto, uma variação do apoio específico proposto pela teoria clássica. Essa proposta está baseada na noção de que tais públicos têm pouca compreensão sobre os ideais democráticos em razão de sua experiência curta neste regime, entretanto, têm percepções claras sobre os diferenciais de desempenho (principalmente econômico) através da comparação entre o que havia antes e a nova realidade política.

Através de modelos de regressão, Mishler e Rose testam o rendimento de cada uma das abordagens e constatam que a idealista, apesar de útil para democracias estáveis, não explica de maneira satisfatória o apoio ao regime nas novas democracias, nas democracias não-estáveis e nos regimes em transição. Esse teste incluiu o Brasil no grupo dos regimes em transição, mas como os autores realizaram uma análise agregada destes conjuntos de nações, as particularidades da tese não puderam ser verificadas no nível das unidades nacionais.

Inspirados por esse debate recente, na próxima seção propomos a verificação da pertinência desta abordagem realista para o caso brasileiro tratado em separado, procurando identificar qual o rendimento explicativo desta perspectiva que privilegia a avaliação racional dos cidadãos acerca do desempenho concreto do regime. 
RIBEIRO, E. A.Bases da legitimidade democrática no Brasil: adesão a valores e avaliação...

\title{
Bases da legitimidade democrática no Brasil
}

A partir da utilização do banco de dados produzidos pelo projeto World Values Survey, em sua sondagem de 1995-1997², iniciamos essa seção com a apresentação do modelo inicialmente empregado na análise.

A primeira difícil tarefa que enfrentamos foi a de identificar uma medida razoável de legitimidade. Trata-se de algo complexo, pois precisamos selecionar uma única variável para ocupar a posição de dependência em uma equação composta por várias outras independentes.

Muito freqüentemente as sondagens realizadas em nível nacional e mundial se valem de questões como essa:

\begin{abstract}
"Vou descrever vários tipos de sistemas políticos e gostaria que você pensasse sobre cada um como formas de governar esse país. Para cada um poderia dizer se é muito bom, bom, mal ou muito mal. Havendo um sistema político democrático." (WVS, 1995-1997)
\end{abstract}

O pressuposto básico que orienta a formulação desta questão é o de que os indivíduos entrevistados têm clareza suficiente acerca dos significados da palavra democracia, o que é, no mínimo, questionável. Como argumentam Mishler e Rose (2001), essa condição não pode ser assegurada nem mesmo em nações com longo histórico democrático.

Se nem ao menos no interior da academia as características fundamentais desta forma de governo são objetos de consenso, a situação é ainda mais complexa quando se tratam de populações que apenas recentemente vivem sob instituições democráticas.

A título de exemplo, Seligson (2001), em estudo comparativo envolvendo populações da Costa Rica e do Chile, identificou que para os habitantes desse primeiro país a liberdade civil seria um princípio básico para a democracia, enquanto os chilenos privilegiam o livre mercado e o capitalismo nas suas concepções.

Diante desta imprecisão, ao invés de variáveis que se utilizam do termo democracia, a medida aqui empregada corresponde à seguinte questão:

As pessoas têm diferentes visões sobre o sistema de governo deste país. Aqui temos uma escala que mede como as coisas vão: 1 significa muito ruim; 10 significa muito bom. Onde nesta escala você colocaria o sistema político que existe hoje?

\footnotetext{
2 Infelizmente, a sondagem realizada em 1999-2002 não incluiu o Brasil. A amostra para nosso país é composta por 1149 entrevistas. Os responsáveis pela distribuição dos dados em nível nacional é o Centro de Estudos de Opinião Pública da Universidade Estadual de Campinas, a quem agradecemos.
} 
Por não fazer uso de termos ambíguos, essa questão pode ser aplicada em diferentes contextos políticos, inclusive naqueles em que o sistema não é democrático.

Selecionada a variável dependente, foi preciso adicionar ao modelo outras medidas que poderiam influenciar os graus de legitimidade manifestos pelos indivíduos. Como nossa intenção era testar a validade da abordagem realista, que privilegia a avaliação supostamente racional dos cidadãos acerca do desempenho do regime, foi preciso inicialmente selecionar questões compatíveis com esse empreendimento.

Nosso ponto de partida para essa tarefa foi a compreensão de que a satisfação dos indivíduos em relação ao desempenho do regime vigente é proporcional à sua percepção sobre os rendimentos que este the proporciona. Nos termos das teorias racionalistas, a renda de utilidade que o indivíduo pensa receber é que irá influenciar sua avaliação positiva ou negativa.

Sendo assim, as duas primeiras informações relevantes dizem respeito à percepção dos cidadãos acerca de sua atual situação econômica, que pode ser verificada através das respostas às perguntas sobre o nível de renda (1) e o seu grau satisfação com a situação financeira familiar (2).

Como a avaliação se dá geralmente em termos comparativos e em relação a períodos de tempo distintos, também selecionamos uma medida de desempenho do regime há dez anos atrás (3) e outra sobre a expectativa do entrevistado acerca do desempenho do regime daqui a dez anos (4). Seria interessante também incluir uma variável referente à avaliação do regime que antecedeu a democracia em nosso país, entretanto, tal medida não se encontra disponível para o caso brasileiro na base de dados do WVS. ${ }^{3}$

A quinta variável selecionada diz respeito à percepção sobre a corrupção (5). Esse é um importante problema em escala mundial, afetando fortemente as democracias estejam elas consolidadas ou não (POWER e GONZÁLEZ, 2003). No caso das chamadas jovens democracias, nas quais o apoio abstrato ao regime ainda é escasso, é plausível supor que os efeitos da percepção de que a corrupção se espalha pelo poder público são ainda mais danosos.

Selecionamos também uma medida de avaliação de desempenho que tem como objeto específico as lideranças políticas que operam as instituições fundamentais do regime em nível nacional (6).

Finalmente, também optamos por incorporar ao modelo medidas de confiança em instituições políticas e alguns de seus operadores (7, 8, 9, 10 e 11) por entender que essas variáveis dizem respeito à dimensão específica do apoio ao

\footnotetext{
3 A questão V151 do questionário do WVS foi construída de modo a ser aplicada em três diferentes contextos: 1) países de formação comunista, 2) países que recentemente (até 10 anos) passaram por mudanças de regime e 3) países que não passaram por tais mudanças recentemente. A avaliação do regime anteriormente existente só é coletada nos países que se enquadram no segundo grupo.
} 
regime. O pressuposto que nos orienta aqui é o de que são as avaliações sobre o funcionamento concreto dos partidos, parlamentos, governos e outras instituições, bem como as percepções sobre o desempenho de seus principais operadores (deputados, senadores, presidente e funcionários públicos em geral) que produzem as oscilações nos níveis de confiança institucional.

Uma vez estabelecido o modelo que incorpora variáveis relacionadas com a avaliação supostamente racional realizada pelos indivíduos em relação ao sistema político, passamos agora a incorporação de outras medidas que se contrapõem a essa abordagem.

Para identificar e controlar os possíveis efeitos de variáveis sóciodemográficas sobre os níveis de legitimidade, selecionamos as variáveis idade (12), nível educacional (13) e classe social subjetiva ${ }^{4}(14)$.

O contraponto mais importante, entretanto, é proporcionado pela inserção de medidas que se referem, de maneira direta ou indireta, à adesão dos entrevistados a alguns valores entendidos como fundamentais à democracia. Com esse procedimento, opomos em um mesmo modelo as abordagens idealista e realista. Nestas variáveis, a despeito da sua ambigüidade, o termo democracia é amplamente utilizado:

A democracia pode ter seus problemas, mas é melhor do que qualquer outra forma de governo. (concordo muito/concordo/discordo/discordo muito) (15)

Na democracia, o sistema econômico não funciona bem.

(concordo muito/concordo/discordo/discordo muito) (16)

Democracias trazem indecisão e muitas discussões.

(concordo muito/concordo/discordo/discordo muito) (17)

Democracias não são boas para manter a ordem.

(concordo muito/concordo/discordo/discordo muito) (18)

O interesse por política (19), variável presente nos estudos sobre cultura política desde o trabalho pioneiro de Almond e Verba (1989), também foi inserido nesta bateria que se refere à adesão a valores congruentes com a democracia.

Ainda nesta mesma dimensão valorativa, tratamos de incorporar ao modelo o auto-posicionamento dos entrevistados em relação ao espectro ideológico (20) que vai da esquerda à direita. Apesar dos problemas metodológicos que esse tipo de variável envolve (PERISSINOTTO e BRAUNERT, 2006), a sua inclusão pode ser interessante, pois possibilita a análise do impacto da filiação ideológica sobre os níveis de legitimidade.

\footnotetext{
4 Essa variável não se refere a critérios objetivos como renda ou posição na estrutura produtiva, mas à autodefinição dos indivíduos como representantes das classes alta, média alta, média baixa, trabalhadora e baixa.
} 
Encerrando esse grupo, incluímos também uma medida que recentemente tem sido empregada para identificar a adesão a um conjunto de valores que estariam fortemente relacionados com a implantação e consolidação de regimes democráticos (INGLEHART, 1990; 1997; INGLEHART e WELZEL, 2005). Trata-se do índice de pós-materialismo (21) construído a partir da adesão dos indivíduos a valores que enfatizam a auto-expressão e a racionalidade, em oposição aos valores de sobrevivência e tradicionais.

Com o mesmo objetivo de controlar impactos externos sobre o modelo inicial, introduzimos também três variáveis que estão diretamente ligadas ao que Putnam (1996) conceitua como capital social: duas medidas de participação voluntária em associações $^{5}$ (22 e 23) e uma de confiança interpessoal (24). De acordo com os autores adeptos dessa abordagem, o associativismo e a confiança seriam fatores fundamentais para a explicação do êxito ou do desempenho de democracias. Não nos interessa nesse momento analisar a pertinência desta complexa afirmação, mas apenas identificar a influencia do ativismo voluntário e da confiança interpessoal sobre o nível de apoio à democracia na presença de todas as demais variáveis já selecionadas.

Antes de apresentamos os resultados do modelo, precisamos verificar o grau de legitimidade do atual regime democrático entre os brasileiros, medido a partir da variável selecionada como independente (Tabela 1). Na escala de dez pontos, a maioria da amostra se posicionou nos níveis inferiores, ou seja, a avaliação do regime atualmente vigente em nosso país era majoritariamente negativa no momento em que os dados foram coletados. Os percentuais acumulados nos pontos 3 e 4 são, respectivamente, de 51,8 e 71,7. A média de avaliação foi de 3,2 e o seu desvio padrão de 2,6.

\footnotetext{
5 Através do emprego da técnica de análise fatorial, identificamos uma divisão entre as questões que tratam da participação dos entrevistados em associações voluntárias, de modo que construímos dois índices diferentes para agrupar melhor os itens. O primeiro índice, que chamamos de Ativismo Voluntário I, é composto pela participação em organizações religiosas, artísticas/educacionais, ambientais e de caridade. O segundo, Ativismo Voluntário II, por sua vez, reúne a participação em sindicatos, partidos e organizações profissionais.
} 
RIBEIRO, E. A.Bases da legitimidade democrática no Brasil: adesão a valores e avaliação...

TABELA 1 - Avaliação do regime atual

\begin{tabular}{|c|c|c|}
\hline Avaliação & $\%$ & $\%$ Acum. \\
\hline 0 (Muito ruim) & 22,3 & 22,3 \\
\hline 1 & 9,0 & 31,3 \\
\hline 2 & 11,1 & 42,3 \\
\hline 3 & 9,4 & 51,8 \\
\hline 4 & 20,0 & 71,7 \\
\hline 5 & 10,4 & 82,2 \\
\hline 6 & 5,4 & 87,6 \\
\hline 7 & 5,3 & 92,9 \\
\hline 8 & 1,7 & 94,6 \\
\hline 9 (Muito bom) & 5,4 & 100,0 \\
\hline Média & \multicolumn{2}{|c|}{3,2} \\
\hline Desvio Padrão & \multicolumn{2}{|c}{2,6} \\
\hline
\end{tabular}

Fonte: WVS 1995-1997.

Ainda que as medidas sejam diferentes, é interessante notar que esses dados indicam uma situação ligeiramente mais negativa do que as encontradas por pesquisas que utilizam medidas idealistas, tal como definimos na seção anterior. Moisés (1995), em sondagem realizada entre os anos de 1989 e 1993, encontrou um mínimo de $43 \%$ dos brasileiros preferindo a democracia a qualquer outra forma de governo. O Instituto Latinobarômetro, em sua sondagem de 2001, encontrou $31 \%$ para essa mesma questão.

Podemos concluir que a legitimidade democrática em nosso país, independente da medida utilizada, não está garantida, o que torna o estudo dos seus determinantes ainda mais relevante.

Com esse objetivo, são apresentados abaixo (Tabela 2) os resultados de um modelo de regressão que estima o impacto de cada uma das vinte e quatro variáveis listadas anteriormente sobre a escala que mede a avaliação dos indivíduos acerca do regime atualmente existente.

Independentemente da significância estatística de cada variável, arbitrariamente listamos na segunda coluna (B) os coeficientes não-padronizados. É importante lembrar, todavia, que esses coeficientes não servem para comparar os feitos entre as variáveis, uma vez que as unidades de medida não são homogêneas. $\mathrm{Na}$ terceira coluna apresentamos apenas os coeficientes padronizados das variáveis que atingiram o mínimo de significância estatística e produziram um impacto de pelos menos 0,05 sobre a variável dependente. 
OPINIÃO PÚBLICA, Campinas, vol. 13, no 1, Junho, 2007, p.74-96

TABELA 2

Estimativas sobre a avaliação no regime atual incluindo todas as variáveis

\begin{tabular}{|c|c|c|}
\hline Variáveis & $\mathrm{B}$ & Beta \\
\hline Nível de renda & $\cdot, 049$ & \\
\hline Satisfação com situação financeira familiar & ,029 & \\
\hline Avaliação do sistema político há 10 anos & ,084 & ,090 \\
\hline Expectativa em relação ao sistema político daqui a 10 anos & ,221 & ,257 \\
\hline Percepção sobre a corrupção & $\cdot, 034$ & \\
\hline Satisfação com as lideranças políticas &, 564 &, 221 \\
\hline Confiança no congresso/deputados e senadores & $\cdot, 023$ & \\
\hline Confiança no funcionalismo público & ,209 & ,075 \\
\hline Confiança no governo &, 185 & ,074 \\
\hline Confiança nos partidos políticos & ,271 &, 101 \\
\hline Confiança no sistema judiciário & $\cdot, 100$ & \\
\hline Idade & ,002 & \\
\hline Classe social (subjetiva) & 101 & \\
\hline Nível educacional & 042 & \\
\hline $\begin{array}{c}\text { Democracia pode ter seus problemas, mas } \\
\text { é a melhor forma de governo. }\end{array}$ &, 053 & \\
\hline Na democracia o sistema econômico não funciona bem & $\cdot, 184$ & $\cdot, 073$ \\
\hline A democracia leva à indecisão. & $\cdot, 082$ & \\
\hline A democracia não é boa para manter a ordem. & $\cdot, 123$ & $\cdot, 053$ \\
\hline Interesse por política &, 144 & ,056 \\
\hline Posicionamento na escala esquerda - direita & .034 & \\
\hline Índice de pós-materialismo & $\cdot, 117$ & $\cdot, 052$ \\
\hline Participação voluntária I &, 127 & \\
\hline Participação voluntária II &,- 079 & \\
\hline Confiança interpessoal & 636 & \\
\hline $\mathrm{R}^{2}$ Ajustado & \multicolumn{2}{|c|}{$31 \%$} \\
\hline
\end{tabular}

Método: Enter

Fonte: WVS 1995-1997

Como os coeficientes padronizados (Beta) indicam cinco das variáveis ligadas à abordagem realista, na presença das demais medidas, não influenciam de maneira significativa a avaliação do regime político atual.

Renda e percepção sobre a situação financeira familiar parecem não influenciar a avaliação que os cidadãos fazem do sistema político em que vivem atualmente. Esse resultado contraria parcialmente a tendência encontrada por 
RIBEIRO, E. A.Bases da legitimidade democrática no Brasil: adesão a valores e avaliação...

Mishler e Rose (2001) no nível mundial, pois o segundo item aparece como significativo no modelo que os mesmos propõem, ainda que o coeficiente padronizado seja baixo $(0,07)$. Entre os cidadãos brasileiros a percepção sobre a situação econômica particular parece estar relativamente desligada do desempenho do regime.

A percepção sobre o quanto a corrupção está disseminada na administração pública também não demonstrou exercer impacto significativo sobre a variável dependente. Isso não significa que a corrupção não esteja sendo percebida pela população nacional, pois $57,9 \%$ dos entrevistados acreditam que quase todos os ocupantes de cargos públicos estão envolvidos em práticas desta natureza. Como poderíamos esperar, o coeficiente é negativo, indicando que a relação entre as variáveis é inversa, entretanto, na presença das demais medidas o efeito dessa percepção sobre a avaliação do sistema político se torna bastante reduzido.

Dentre as variáveis de confiança institucional, apenas as que se referem ao congresso/deputados e senadores e ao sistema judiciário não tiveram impacto significativo, o que poderia ser explicado pelo fato de que, na democracia brasileira, o poder executivo possui uma clara preponderância em relação aos dois outros poderes fundamentais (PEREIRA e MUELLER, 2000). Entre os pesquisados, 45,9\% declararam não confiar no congresso e o percentual acumulado entre as opções "não confia" e "confia pouco" para o sistema judiciário alcançou 45 pontos.

Nenhuma das variáveis sócio-demográficas se mostrou significativamente importante no contexto do modelo elaborado. A autopercepção em relação à classe social foi a que alcançou o maior coeficiente padronizado $(0,04)$, ainda assim não atingindo o índice mínimo para significância estatística.

Sobre as variáveis relacionadas ao apoio difuso e à abordagem idealista, é interessante notar que aquela obtida através do grau de concordância dos entrevistados à afirmação "a democracia pode ter seus problemas, mais ainda é a melhor forma de governo" não apresentou impacto significativo sobre a avaliação do regime atual. Mais de $80 \%$ da amostra, cumulativamente, escolheram as opções "concorda" e "concorda muito".

Essa situação pode indicar que o reservatório que sustenta o apoio à democracia per se ainda é significativo e tem evitado a corrosão do apoio ao regime, apesar das avaliações de desempenho concreto serem negativas. Entretanto, como já abordamos anteriormente, pode também ser indicativo de que a utilização de questões que pressupõem a compreensão por parte dos entrevistados acerca do significado do termo democracia pode produzir medidas equivocadas.

O auto-posicionamento na escala ideológica também não alcançou níveis significativos de influência sobre a variável independente, demonstrando que os diferenciais na avaliação do sistema atual não podem ser imputados a posturas ideológicas de direita ou esquerda. 
O mesmo aconteceu com as duas medidas de participação política voluntária, ou seja, o fato de atuarem em instituições políticas ou sociais não tem impacto considerável sobre a avaliação que os indivíduos fazem do regime atual.

Para além desta análise sobre o relacionamento entre as variáveis, vale apontar que os níveis de participação na amostra nacional são muito baixos mesmo quando não se trata da atuação em organizações políticas. No primeiro índice somatório, que mede a adesão a organizações e associações artísticas, educacionais, religiosas ou esportivas, em uma escala que vai de 0 a 4 , a média foi de apenas 0,6 . Mais de $58 \%$ dos entrevistados declararam não ter nenhuma participação.

No segundo índice somatório a situação é semelhante, pois a média foi de 0,9 , em uma escala que vai de 0 a 7 . Da mesma maneira, mais de $50 \%$ da amostra não possui em qualquer tipo de atuação em organizações de natureza política.

A variável confiança interpessoal, normalmente utilizada nos estudos sobre capital social, também não apresentou influência considerável no contexto do modelo. A maioria absoluta $(97,2 \%)$ dos incluídos na sondagem se situou no nível mínimo de confiança, o que equivale à afirmação "devemos sempre tomar cuidado no tratamento com as pessoas". Essa desconfiança, entretanto, parece estar desligada da avaliação que os cidadãos fazem do sistema político vigente.

O interesse por política e o índice de pós-materialismo apresentaram coeficientes padronizados apenas ligeiramente superiores ao mínimo de 0,05, o que denota um impacto reduzido sobre a medida de legitimidade.

Esses resultados indicaram a possibilidade de exclusão de um número considerável de variáveis, o que poderia contribuir para o melhor ajustamento do modelo. Sendo assim, em um segundo momento da análise, optamos pelo método stepwise, que automaticamente apresenta uma lista de modelos indicando qual deles possui o maior potencial explicativo. Sendo assim, a tabela abaixo (Tabela 3) traz os resultados envolvendo apenas as variáveis que exercem influência significativa e contribuem para o ajuste do modelo. 
RIBEIRO, E. A.Bases da legitimidade democrática no Brasil: adesão a valores e avaliação...

TABELA 3

Estimativas sobre a avaliação do regime atual (modelo com melhor ajuste)

\begin{tabular}{lcr}
\hline \multicolumn{1}{c}{ Variáveis } & B & Beta \\
\hline Avaliação do sistema político existente há 10 anos &, 086 &, 092 \\
\hline Expectativa em relação ao sistema político daqui a 10 anos &, 223 &, 260 \\
\hline Satisfação com as lideranças políticas &, 581 &, 227 \\
\hline Confiança no governo &, 207 &, 082 \\
\hline Confiança nos partidos políticos &, 276 &, 103 \\
\hline Confiança no funcionalismo público &, 211 &, 075 \\
\hline Na democracia o sistema econômico não funciona bem &,- 228 &,- 090 \\
\hline A democracia não é boa para manter a ordem & $\cdot, 157$ &,- 068 \\
\hline$R^{2}$ Ajustado & $31 \%$ \\
\hline Método: Stepwise. & &
\end{tabular}

Como podemos verificar, o modelo que melhor explica a variação na avaliação do sistema atualmente existente é composto por apenas oito variáveis que obtiveram coeficientes padronizados significativos. Notem que o interesse por política e o índice de pós-materialismo, que no modelo completo obtiveram coeficientes padronizados ligeiramente superiores a 0,05, foram excluídos neste momento pois a sua presença implicava em redução do poder explicativo do conjunto das variáveis.

Mais de $68 \%$ dos entrevistados manifestaram nenhum ou pouco interesse em política, o que deve ser interpretado como algo negativo, uma vez que tal medida é utilizada desde o estudo pioneiro de Almond e Verba (1989) como um indicador importante da cultura cívica de uma população.

No que se refere à adesão aos valores pós-materialistas, tal como definidos por Inglehart, a situação encontrada é compatível com as afirmações da teoria do desenvolvimento humano em escala mundial. Desde a década de 1970, Inglehart (1990; 1997) tem identificado manifestações do que classifica como uma síndrome de valores pós-materialistas nos países economicamente desenvolvidos. Essa mudança se caracterizaria pela substituição dos valores tradicionais e de sobrevivência por valores racionais e de auto-expressão.

Essa alteração seria impulsionada pelos níveis de bem-estar e satisfação material dos indivíduos, que os conduziriam a preocupações pós-materialistas. As conseqüências políticas deste processo seriam de grande importância, pois ao enfatizarem a auto-expressão em lugar da sobrevivência física os cidadãos pressionariam os sistemas políticos à democratização (INGLEHART e WELZEL, 2005). 
Neste sentido, como o Brasil ainda não atingiu níveis elevados de desenvolvimento econômico e está longe de superar os problemas referentes à satisfação das necessidades materiais da maioria de sua população, é compreensível que em uma escala que vai de 0 a 5 tenhamos encontrado uma média de 2,2, com um percentual acumulado de mais de $58 \%$ entre os níveis 0 e 2.

Essa situação negativa em ambas as variáveis, entretanto, não produziu impacto suficientemente relevante para serem incluídas no modelo que apresentamos acima Tabela 3.

A tese de que em democracias sem longa tradição o apoio ao sistema político se deve mais às experiências recentes positivas do que à adesão a valores e ideais abstratos (MISHLER e ROSE, 2001) parece ser parcialmente corroborada pelos resultados encontrados neste segundo momento de análise.

Como já destacamos anteriormente, as variáveis culturalistas que normalmente são empregadas por diferentes abordagens para explicar os níveis de legitimidade democrática foram excluídas em razão de seu impacto inexpressível. Como pretendemos argumentar agora, as medidas mantidas estão relacionadas com o que podemos classificar como avaliações mais ou menos racionais e conscientes produzidas pelos cidadãos em relação ao funcionamento ou desempenho concreto do sistema e de suas principais instituições.

As duas primeiras medidas que apresentam coeficientes padronizados relevantes se referem às avaliações anteriores e posteriores do sistema político. Neste sentido, servem para identificar o impacto da percepção acerca do desempenho recente e do que se espera do futuro. No primeiro caso, verificamos que cada ponto adicional na avaliação do sistema dez anos atrás acrescenta 0,09 desvio padrão à avaliação do sistema atual.

A expectativa em relação ao sistema para daqui a dez anos, entretanto, apresentou um impacto bastante superior (Beta de 0,26). A interpretação destes valores indica que, apesar do impacto da experiência passada recente ser importante, o fator tendencial merece maior atenção.

Chamamos de fator tendencial a reta que é composta pelas avaliações medidas em pelo menos dois momentos diferentes em uma linha temporal. Neste caso, os dados referentes à amostra utilizada indicam uma tendência ligeiramente positiva para o Brasil, pois a média na avaliação anterior é de 3,6, enquanto a expectativa para o futuro próximo alcança 4,9.

O segundo maior impacto encontrado se refere à avaliação do desempenho das lideranças políticas. É interessante notar que a aprovação neste item superou os 50 pontos percentuais. Mais precisamente, $57,3 \%$ dos entrevistados se colocaram entre as opções "satisfeito" e "muito satisfeito".

Com coeficiente padronizado de 0,23, a relação entre essa avaliação de desempenho dos operadores das instituições políticas e o apoio ao sistema atual 
RIBEIRO, E. A.Bases da legitimidade democrática no Brasil: adesão a valores e avaliação...

corrobora a afirmação de que medidas ligadas ao cálculo relativamente consciente dos cidadãos possuem considerável capacidade explicativa sobre a legitimidade em jovens democracias como a nossa.

Entre as medidas de confiança institucional, três se mostraram relevantes. Como defendemos no momento em que apresentamos as variáveis que comporiam o modelo inicialmente proposto, os níveis de confiança nas instituições centrais do sistema democrático, bem como de alguns de seus operadores, podem ser vistos como componentes do apoio específico pois, apesar de serem também formados por processos de socialização relativamente prolongados, são sensíveis às flutuações significativas em razão de fenômenos conjunturais relacionados ao desempenho. Como afirma Moisés, os indivíduos se identificam com as instituições "porque aprenderam a fazê-lo através de processos sucessivos de transmissão de seu significado de geração a geração mas, principalmente, porque suas experiências concretas, ao longo de sua vida adulta, qualifica-os para avaliar racionalmente o seu desempenho" (MOISÉS, 2005, p. 53).

Tal interpretação nos habilita a considerar essas medidas como integrantes da abordagem realista da legitimidade, que leva em consideração a capacidade dos indivíduos para produzirem avaliações racionais sobre o desempenho das instituições.

Os resultados encontrados em nossa análise, ao incluir apenas medidas de confiança no governo, partidos e funcionalismo público, apontam para questões interessantes.

A primeira delas diz respeito à relação entre os poderes fundamentais da nossa democracia na percepção dos cidadãos. É sabido que no contexto democrático brasileiro o poder executivo apresenta uma proeminência sobre os demais, exercida por meio de peças jurídicas como as medidas provisórias e outros mecanismos menos institucionalizados (PEREIRA e MUELLER, 2000). Neste sentido, é compreensível a exclusão dos níveis de confiança nas instituições legislativas e no sistema judiciário no modelo com melhor ajustamento.

Da mesma forma, era previsível a ocorrência de coeficiente significativo na confiança no governo/executivo, possivelmente visto pelos entrevistados como a instituição fundamental do sistema democrático concretamente existente.

A segunda questão que desponta dos resultados diz respeito à intensidade do contato estabelecido entre os cidadãos e as instituições. Ou seja, poderíamos supor inicialmente que quanto maior fosse a freqüência e intensidade das experiências dos cidadãos com as diferentes instituições políticas, maior seria o impacto da confiança depositada nelas sobre a avaliação do sistema político.

Não dispomos de evidências empíricas suficientes para afirmar que a preponderância política do executivo também se converte em maior visibilidade pública e proximidade em relação aos cidadãos, entretanto, acreditamos que a 
exclusão dos níveis de confiança nas instituições legislativas e no sistema judiciário no nosso modelo com melhor ajustamento pode ser uma indicação inicial de que tal fenômeno possa estar ocorrendo. A confirmação futura dessa hipótese poderia explicar o fato de termos verificado que a variável relacionada ao poder executivo, diferentemente dos demais, exerce impacto sobre a variável dependente.

Ainda sobre a questão da proximidade, verificamos que o nível de confiança depositado no funcionalismo público, com o qual os cidadãos estabelecem contatos concretos relativamente freqüentes, impacta significativamente a avaliação do sistema político.

Esse tema pode ser relacionado com a questão do papel da informação na teoria econômica da democracia de A. Downs (1999). Os atores políticos podem não ser informados suficientemente bem para analisarem racionalmente todos os fatores que envolvem o apoio político a um partido ou sistema político, mas em algumas áreas específicas o seu cálculo pode ser mais consciente e acertado. Como ilustramos anteriormente, um cidadão que tenha sido recentemente vítima de assalto pode ter obtido informação qualificada acerca do tema segurança pública em razão do seu interesse. Investindo tempo e outros recursos, esse indivíduo dotado de informação pode tomar uma decisão mais racional em relação a esse tema específico.

Como os contatos e experiências dos cidadãos comuns com o funcionalismo público são bem mais freqüentes do que aquelas travadas com as instituições parlamentares (congresso/deputados e senadores) ou judiciais os seus relativos impactos sobre os níveis de apoio ao sistema político também deveriam ser superiores.

$\mathrm{Na}$ amostra nacional verificamos percentuais acumulados de 40,9 e 51,4 pontos entre as opções "não confia" e "confia pouco" para o funcionalismo público e governo/executivo, respectivamente. Essa situação negativa possui um poder explicativo considerável sobre os baixos níveis de apoio ao sistema político existente.

Causou certa surpresa a permanência da confiança nos partidos políticos no modelo, sobretudo porque a mesma alcançou o maior coeficiente $(0,10)$ dentre as variáveis relacionadas a essa dimensão específica. Essa situação não pode ser explicada pelos argumentos construídos anteriormente, pois as instituições partidárias não são aquelas com as quais os cidadãos mais freqüentemente se relacionam. A relação entre apoio às instituições partidárias e a legitimidade do sistema em nosso país, portanto, demanda análises específicas que possam esclarecer os pormenores da questão.

As duas últimas variáveis que se mantiveram fazem parte do grupo de questões normalmente utilizadas por abordagens idealistas nos estudos de 
legitimidade. Tal grupo é formado por medidas que se prestam à identificação da adesão dos cidadãos aos valores e ideais ligados à democracia.

A permanência de duas dessas variáveis em nosso modelo, entretanto, não invalida as conclusões a que chegamos até aqui, pois elas se situam na tênue linha que separa a adesão a valores e a avaliação racional do desempenho. Propomos a hipótese de que ao se posicionar diante das afirmações "na democracia o sistema econômico não funciona bem" e "a democracia não é boa para manter a ordem" o cidadão brasileiro esteja se valendo muito mais de suas experiências recentes relacionadas ao desempenho econômico e ao controle dos conflitos internos do que de um reservatório de legitimidade abstrato, ou seja, de valores incorporados por longo processo de socialização em ambiente democrático.

Essa hipótese só se justifica em razão da natureza dessas afirmações que remetem o entrevistado diretamente à avaliação do desempenho do sistema político atual. As demais, que se referem a uma dimensão mais abstrata, não alcançaram impacto significativo. Essa proposição também pode ser verificada quando comparamos os coeficientes das duas variáveis que se mantiveram: a que se refere à dimensão econômica alcançou valores superiores.

Desta forma, mesmo quando medidas associadas à abordagem idealista se mostram relevantes, é preciso ter em mente que algumas delas podem dizer respeito muito mais à avaliação do desempenho dos sistemas políticos no curto e médio prazo do que à adesão a valores e ideais.

Em síntese, os resultados apresentados na última tabela favorecem a conclusão de que a chamada abordagem realista possui rendimentos interessantes para a análise do tema da legitimidade para o caso nacional. Devido ao caráter recente de nossa experiência com o sistema democrático, parece ser razoável acreditar que análises que privilegiam a adesão a valores e ideais podem produzir resultados questionáveis para contextos similares ao nosso. Neste sentido, seria útil a aplicação de modelos alternativos inspirados no pressuposto de que os indivíduos são capazes de produzir avaliações relativamente racionais sobre o desempenho do sistema político e, a partir deste procedimento, apoiá-lo ou rejeitá-lo.

\section{Considerações finais}

Medidas de legitimidade baseadas na adesão dos cidadãos a valores e ideais congruentes com a democracia, apesar de serem amplamente utilizadas, podem não ser interessantes quando aplicadas a países que passaram apenas recentemente por processos de democratização. A generalização é inviável porque as populações de jovens democracias não possuem a experiência prolongada com esse sistema político, necessária à internalização de tais valores. 
Como procedimento alternativo, Mishler e Rose (2001) propõem uma abordagem realista que enfatiza a avaliação racional que os indivíduos fazem do desempenho do sistema político como medida de legitimidade.

Nosso objetivo nesse artigo foi verificar a validade dessa última formulação para a identificação dos determinantes da legitimidade no caso da jovem democracia brasileira. Valendo-nos de uma medida realista de apoio ao sistema (sem o emprego do discutível termo democracia), buscamos identificar que ordem de variáveis produziria impacto considerável sobre a adesão dos indivíduos ao regime democrático vigente.

Os resultados da análise apresentada corroboram a abordagem realista, pois o conjunto das variáveis que alcançaram influência significativa sobre a avaliação do sistema político nacional diz respeito às percepções dos cidadãos em relação ao desempenho de diferentes componentes da democracia realmente existente. Neste caso, podemos afirmar que a experiência recente com o sistema político tende a produzir maior impacto sobre os níveis de legitimidade democrática no Brasil.

É importante destacar que essa conclusão não implica na desconsideração da adesão aos valores e ideais democráticos. Adotando a terminologia de Easton (1968), entendemos que o apoio difuso ou abstrato é tão importante quanto o específico na configuração dos níveis de legitimidade de um sistema político. Altos níveis de legitimidade dependem de avaliações de desempenho positivas, mas também da disseminação entre os cidadãos de valores e ideais compatíveis com processos de democratização.

Esse reconhecimento, entretanto, não pode nos impedir de interrogar sobre a preponderância de uma destas dimensões do apoio em contextos particulares, pois é plausível supor que a dinâmica que envolve ambas se altere na medida em que se alteram os ambientes sociais, econômicos, políticos e institucionais. Foi justamente um exercício de questionamento desta natureza que tentamos aqui realizar. 
RIBEIRO, E. A.Bases da legitimidade democrática no Brasil: adesão a valores e avaliação...

\section{Referências bibliográficas}

ALMOND, G.; VERBA, S. The Civic Culture: political attitudes and democracy in five nations. New York: Sage, 1989.

ALMOND, G; POWELL JR, B. Uma teoria da política comparada. Rio de Janeiro: Zahar, 1972.

BECKER, G. The Economic Approach to Human Behavior. Chicago: University of Chicago Press, 1976

COLEMAN, J.S. Fundations of social theory. Cambridge, Belknap Press, 1972

DALTON, R.J. Democratic challenges, democratic choices: the erosion of political support in advanced industrial democracies. Oxford: Oxford University Press, 2004.

DOWNS, A. Uma teoria econômica da democracia. São Paulo: Edusp, 1999

EASTON, D. A systems analysis of political life. New York: Wiley, 1965.

D. Uma teoria de análise política. Rio de Janeiro: Zahar, 1968

INGLEHART, R. Cultural Shift in Advanced Industrial Society. Princeton: Princeton University Press, 1990.

R. Modernization and Postmodernization: cultural, economic and political change in 43 societies. Princeton, NJ: Princeton University Press, 1997.

INGLEHART, R.; WELZEL, C. Modernization, cultural change, and democracy. Cambridge: Cambridge University Press, 2005.

MISHLER, W.; ROSE, R. Political support for incomplete democracies: realist vs. idealist theories and measures. International Political Science Review, vol. 22, n. 4, p. 303-320, 2001.

MOISÉS, J.A. Os brasileiros e a democracia. São Paulo: Ática, 1995.

NEWTON, K.; NORRIS, P. Confidence in public institutions: faith, culture or performance? In: PHARR, S. J.; PUTNAM, R. D. Disaffected democracies: what's troubling the trilateral countries? Princeton: Princeton University Press, 2000. 
NORRIS, P. (ed.). Critical citizens: global support for democratic governance. Oxford: Oxford University Press, 1999.

OLSON, M. A lógica da ação coletiva. São Paulo: Edusp, 1999.

PEREIRA, C.; MUELLER, B. Uma Teoria da Preponderância do Poder Executivo: O Sistema de Comissões no Legislativo Brasileiro. Revista Brasileira de Ciências Sociais, vol. 15, n. 43, p. 45. $67,2000$.

PERISSINOTTO, R.M.; BRAUNERT, M.B. 2006. A direita, a esquerda e a democracia: os valores políticos dos parlamentares paranaenses (1995-2002). Opinião Pública, Campinas, vol. 12, n. 1, p. 114-135, abr-mai. 2006.

PETTIT, P. Republican theory and political trust. In: BRAITHWAITE, V.; LEVI, M. (Eds.). Trust and governance. New York: Sage, 1998.

PHARR, S.J.; PUTNAM, R.D.; DALTON, R.J. A quarter-century of declining confidence. Journal of Democracy, v.11, n.2, p. 5-25, 2000.

POWER, T.J; GONZÁLEZ, J.. Cultura política, capital social e percepções sobre corrupção: uma investigação quantitativa em nível mundial. Revista de Sociologia e Política, n. 25, p. 51 . 69, 2003.

SELIGSON, M.A. Costa Rica exceptionalism: why the 'Ticos' are different. In: CAMP, R.A.(ED.). Citizen views of democracy in Latin American. Pittsburgh: University of Pittsburgh Press, 2001.

SELIGSON, M.A.; BOOTH, J.A.; GÓMEZ, B.M. Os contornos da cidadania crítica: explorando a legitimidade democrática. Opinião Pública, Campinas, vol. 12, n. 1, p. 1·37, abr/mai.2006.

WARREN, M.E.(ed.). Democracy and trust. Cambridge: Cambridge University Press, 2001. 
Anexo

\begin{tabular}{|c|c|c|}
\hline Variável & $N^{\circ}$ WVS & Codificação \\
\hline (1) Nível de renda & V236 & Escala de 1 (baixa) a 10 (alta) \\
\hline $\begin{array}{l}\text { (2) Satisfação com situação financeira } \\
\text { familiar }\end{array}$ & V80 & $\begin{array}{l}\text { Escala de } 0 \text { (nada satisfeito) a } 10 \text { (muito } \\
\text { satisfeito) }\end{array}$ \\
\hline $\begin{array}{l}\text { (3) Avaliação do sistema político há } 10 \\
\text { anos atrás }\end{array}$ & V163 & Escala de 0 (muito ruim) a 9 (muito bom) \\
\hline $\begin{array}{l}\text { (4) Expectativa em relação ao sistema } \\
\text { político daqui a } 10 \text { anos }\end{array}$ & V163i & Escala de 0 (muito ruim) a 9 (muito bom) \\
\hline (5) Percepção sobre a corrupção & V213 & $\begin{array}{l}\text { Escala de } 0 \text { (quase nenhum dos } \\
\text { funcionários está envolvido) a } 3 \text { (quase } \\
\text { todos estão envolvidos) }\end{array}$ \\
\hline $\begin{array}{l}\text { (6) Satisfação com as lideranças } \\
\text { políticas }\end{array}$ & V174 & $\begin{array}{l}\text { Escala de } 0 \text { (muito insatisfeito) a } 3 \text { (muito } \\
\text { satisfeito) }\end{array}$ \\
\hline $\begin{array}{l}\text { (7) Confiança no congresso/deputados e } \\
\text { senadores }\end{array}$ & V155 & $\begin{array}{l}\text { Escala de } 0 \text { (não confia) a } 3 \text { (confia } \\
\text { muito) }\end{array}$ \\
\hline (8) Confiança no funcionalismo público & V156 & $\begin{array}{l}\text { Escala de } 0 \text { (não confia) a } 3 \text { (confia } \\
\text { muito) }\end{array}$ \\
\hline (9) Confiança no governo & V153 & $\begin{array}{l}\text { Escala de } 0 \text { (não confia) a } 3 \text { (confia } \\
\text { muito) }\end{array}$ \\
\hline (10) Confiança nos partidos políticos & V154 & $\begin{array}{l}\text { Escala de } 0 \text { (não confia) a } 3 \text { (confia } \\
\text { muito) }\end{array}$ \\
\hline (11) Confiança no sistema judiciário & V212 & $\begin{array}{l}\text { Escala de } 0 \text { (não confia) a } 3 \text { (confia } \\
\text { muito) }\end{array}$ \\
\hline (12) Idade & $x 003$ & Anos \\
\hline (13) Nível educacional & $\mathrm{X} 025 \mathrm{R}$ & Escala de 1 (baixo) a 3 (alto) \\
\hline (14) Classe social (subjetiva) & x045 & $\begin{array}{l}\text { Escala de } 1 \text { (classe baixa) a } 5 \text { (classe } \\
\text { alta) }\end{array}$ \\
\hline $\begin{array}{l}\text { (15) Democracia pode ter seus } \\
\text { problemas, mas é a melhor forma de } \\
\text { governo. }\end{array}$ & V172 & $\begin{array}{l}\text { Escala de } 0 \text { (discorda muito) a } 3 \\
\text { (concorda muito) }\end{array}$ \\
\hline $\begin{array}{l}\text { (16) Na democracia o sistema } \\
\text { econômico não funciona bem }\end{array}$ & V169 & $\begin{array}{l}\text { Escala de } 0 \text { (discorda muito) a } 3 \\
\text { (concorda muito) }\end{array}$ \\
\hline (17) A democracia leva a indecisão. & V170 & $\begin{array}{l}\text { Escala de } 0 \text { (discorda muito) a } 3 \\
\text { (concorda muito) }\end{array}$ \\
\hline $\begin{array}{l}\text { (18) A democracia não é boa para } \\
\text { manter a ordem. }\end{array}$ & V171 & $\begin{array}{l}\text { Escala de } 0 \text { (discorda muito) a } 3 \\
\text { (concorda muito) }\end{array}$ \\
\hline (19) Interesse por política & V133 & $\begin{array}{l}\text { Escala de } 1 \text { (nenhum interesse) a } 4 \\
\text { (muito interesse) }\end{array}$ \\
\hline $\begin{array}{l}\text { (20) Posicionamento na escala esquerda- } \\
\text { direita }\end{array}$ & V139 & Escala de 1 (direita) a 10 (esquerda) \\
\hline (21) Índice de pós-materialismo & Y001 & $\begin{array}{l}\text { Escala de } 0 \text { (materialista) a } 5 \text { (pós- } \\
\text { materialista) }\end{array}$ \\
\hline
\end{tabular}


OPINIÃO PÚBLICA, Campinas, vol. 13, no 1, Junho, 2007, p.74-96

\begin{tabular}{|l|c|l|}
\hline (22) Participação voluntária I & $\begin{array}{l}\text { V028, V030, } \\
\text { V033, V035 }\end{array}$ & $\begin{array}{l}\text { Índice somatório de 0 a 4. As questões } \\
\text { originalmente apresentavam as opções } \\
\text { "membro ativo = 1/ membro inativo= 2/ } \\
\text { não participa= 3". Após a recodificação } \\
\text { se tornaram binárias: "membro ativo } \\
\text { /membro inativo= 1/ não participa= 0" }\end{array}$ \\
\hline (23) Participação voluntária II & $\begin{array}{c}\text { V031, V032, } \\
\text { V034 }\end{array}$ & $\begin{array}{l}\text { Indice somatório de 0 a 3. As questões } \\
\text { originalmente apresentavam as opções } \\
\text { "membro ativo= 1/ membro inativo= 2/ } \\
\text { não participa= 3". Após a recodificação } \\
\text { se tornaram binárias: "membro ativo } \\
\text { /membro inativo= 1/ não participa= 0". }\end{array}$ \\
\hline (24) Confiança interpessoal & V25 & Binária (0/1) \\
\hline
\end{tabular}

